\title{
Dynamic Output Feedback Linearizing Control of Saturated Induction Motors with Torque per Ampere Ratio Maximization
}

\author{
Sergei Peresada, Serhii Kovbasa, Serhii Dymko \\ Faculty of Electric Power Engineering and Automatics, \\ National Technical University of Ukraine «KPI», \\ Peremogy av. 37, 03056 Kyiv, Ukraine \\ E-mail: sergei.peresada@gmail.com
}

\begin{abstract}
The paper presents a novel maximum torque per Ampere (MTA) controller for induction motor (IM) drives. The proposed controller exploits the concept of direct (observer based) field orientation and guarantees asymptotic torque tracking of smooth reference trajectories and maximizes the torque per Ampere ratio when the developed torque is constant or slowly varying. A dynamic output-feedback linearizing technique is employed for the torque subsystem design. In order to improve torque tracking accuracy a motor magnetizing curve is taken into account during MTA optimization and controller design.

The achieved steady-state system efficiency have been compared experimentally for three types of controllers, namely: standard vector control with constant flux operation, controller based on classic maximization of torque per Ampere ratio for linear magnetic circuit and controller based on MTA strategy for saturated induction motor. It is shown experimentally that the controller designed for saturated induction motor provides not only higher torque per Ampere ratio but also increases power factor and reduces active power consumption hence improving the drive efficiency. Operation with slowly varying torque references has also been analysed. It is shown that the proposed controller is suitable for applications that do not demand an extremely fast dynamic response, for example for electric vehicle drives.
\end{abstract}

Keywords-induction motor, field-oriented control, maximum torque per Ampere ratio, flux saturation.

\section{INTRODUCTION}

Standard Field-Oriented Vector Control (FOC) and advanced FOC [1] of IM have de-facto established an industrial standard for high dynamic performance applications. Vector controlled IM drives typically operate with constant flux magnitude even at low values of torque and provide very good dynamic performance. However the machine efficiency and power factor can be low, especially at small torque values.

The efficiency improvement techniques typically reported in publications adjust the flux level as a function of the electromagnetic torque using various optimization procedures. The flux regulation restricts the drive dynamic performance hence this approach can only be employed in applications not requiring an extremely fast response, for example - in electric vehicle drives. A number of control strategies to optimize different performance objectives are known [2], [3]: minimization of active and total losses, power factor

\author{
Serhiy Bozhko \\ Faculty of Engineering, University of Nottingham, \\ University Park, Nottingham NG7 2RD, United Kingdom \\ E-mail: serhiy.bozhko@nottingham.ac.uk
}

maximization, Maximum Torque per Ampere (MTA) control, maximum torque per voltage control and maximum power transfer. MTA control provides IM operation similar to those provided by active losses minimization method [2].

An important issue for variable flux operation is the machine saturation effect. This effect results in varying machine inductances hence the assumption of linear magnetic circuits, common for standard optimization routines, is no longer valid. The problem of asymptotic torque tracking with MTA optimization for saturated IM is investigated in [4], [5]. Authors propose a nonlinear flux observer which accounts for the machine magnetic saturation. In [4] a linear magnetic circuit is assumed for MTA optimization. The torque tracking controller with MTA optimization for saturated IM [5] is based on static feedback linearization technique and does not provide flux regulation in closed-loop.

This paper aims for improved torque-flux tracking performances based on solutions [4], [5] by considering magnetizing properties during the controller design and MTA optimization. The results of intensive experimental investigations are also presented to analyse efficiency, power factor and torque per Ampere ratio during torque trajectories tracking for considered control methods.

This paper is organized as follows. The IM model and control problem formulation are given in Sections II. The torque tracking MTA controller for saturated IM is designed in Section III. In Section IV the experimental test results are reported followed by the Conclusions of the study.

\section{PROBLEM STATEMENT}

For the purpose of this study the $1 / \lambda$-saturated IM model reported in [6], [7] has been employed. The model assumes that only the magnetizing inductance $\mathrm{L}_{m}$ is saturated hence the leakage inductances are constant, and neglects the crosssaturation inductance so static and dynamic magnetizing inductances are equal. The following definitions are used: $\mathrm{L}_{\mathrm{m}}\left(\mathrm{i}_{\mathrm{m}}\right) \square \psi_{\mathrm{m}}\left(\mathrm{i}_{\mathrm{m}}\right) / \mathrm{i}_{\mathrm{m}}$ is a static inductance of the magnetizing circuit, where $\psi_{m}\left(i_{m}\right)$ - magnetizing curve, $i_{m}$ - magnetizing current; $\quad \mathrm{L}_{1}\left(\mathrm{i}_{\mathrm{m}}\right)=\mathrm{L}_{\mathrm{m}}\left(\mathrm{i}_{\mathrm{m}}\right)+\mathrm{L}_{1 \sigma}, \quad \mathrm{L}_{2}\left(\mathrm{i}_{\mathrm{m}}\right)=\mathrm{L}_{\mathrm{m}}\left(\mathrm{i}_{\mathrm{m}}\right)+\mathrm{L}_{2 \sigma}-$ stator and rotor inductances, respectively, where $\mathrm{L}_{1 \sigma}=$ const and $\mathrm{L}_{2 \sigma}=$ const are stator and rotor leakage inductances. 
Under these assumptions, the two-phase model of saturated IM in an arbitrary rotating reference frame, (d-q), is given as follows:

$$
\begin{aligned}
& \dot{\omega}=\frac{1}{\mathrm{~J}}\left(\mathrm{~T}-\mathrm{T}_{\mathrm{L}}\right) \\
& \mathrm{T}=\mu_{1 \mathrm{~m}}\left(\psi_{\mathrm{d}} \mathrm{i}_{\mathrm{q}}-\psi_{\mathrm{q}} \mathrm{i}_{\mathrm{d}}\right) \\
& \dot{\mathrm{i}}_{\mathrm{d}}=-\gamma_{\mathrm{m}} \mathrm{i}_{\mathrm{d}}+\omega_{0} \mathrm{i}_{\mathrm{q}}+\alpha_{\mathrm{m}} \beta_{\mathrm{m}} \psi_{\mathrm{d}}+\omega \beta_{\mathrm{m}} \psi_{\mathrm{q}}+\frac{\mathrm{u}_{\mathrm{d}}}{\sigma_{\mathrm{m}}} \\
& \dot{\mathrm{i}}_{\mathrm{q}}=-\gamma_{\mathrm{m}} \mathrm{i}_{\mathrm{q}}-\omega_{0} \mathrm{i}_{\mathrm{d}}+\alpha_{\mathrm{m}} \beta_{\mathrm{m}} \psi_{\mathrm{q}}-\omega \beta_{\mathrm{m}} \psi_{\mathrm{d}}+\frac{\mathrm{u}_{\mathrm{q}}}{\sigma_{\mathrm{m}}} \\
& \dot{\psi}_{\mathrm{d}}=-\alpha_{\mathrm{m}} \psi_{\mathrm{d}}+\alpha_{\mathrm{m}} \mathrm{L}_{\mathrm{m}}\left(\mathrm{i}_{\mathrm{m}}\right) \mathrm{i}_{\mathrm{d}}+\omega_{2} \psi_{\mathrm{q}} \\
& \dot{\psi}_{\mathrm{q}}=-\alpha_{\mathrm{m}} \psi_{\mathrm{q}}+\alpha_{\mathrm{m}} \mathrm{L}_{\mathrm{m}}\left(\mathrm{i}_{\mathrm{m}}\right) \mathrm{i}_{\mathrm{q}}-\omega_{2} \psi_{\mathrm{d}} \\
& \dot{\varepsilon}_{0}=\omega_{0}
\end{aligned}
$$

where $\mathrm{u}_{\mathrm{d}}, \mathrm{u}_{\mathrm{q}}$ are stator voltage components (here and throughout the paper subscripts $d$ and $q$ denote vector variable components in the (d-q) reference frame), $i_{d}, i_{q}$ are stator currents, $\psi_{\mathrm{d}}, \psi_{\mathrm{q}}$ define the rotor flux, $\omega$ is the rotor speed, $\mathrm{T}$ is the electromagnetic torque, $T_{L}$ is the load torque and $\varepsilon_{0}$ is the angular position of the (d-q) reference frame with respect to a fixed stator reference frame (a-b) in which physical variables are defined. Slip frequency is defined as $\omega_{2}=\omega_{0}-\omega$, and $J$ is the total rotor inertia. One pole pair is assumed without loss of generality. In the model (1) constants (all positive) related to IM electrical parameters are given by:

$$
\begin{aligned}
& \alpha_{m}=\frac{R_{2}}{L_{2}\left(i_{m}\right)}, \beta_{m}=\frac{L_{m}\left(i_{m}\right)}{L_{2}\left(i_{m}\right) \sigma_{m}}, \\
& \gamma_{m}=\frac{R_{1}}{\sigma}+\alpha_{m} \beta_{m} L_{m}\left(i_{m}\right), \\
& \sigma_{m}=L_{1}\left(i_{m}\right)-\frac{L_{m}^{2}\left(i_{m}\right)}{L_{2}\left(i_{m}\right)}, \\
& \mu_{1 m}=\frac{3 L_{m}\left(i_{m}\right)}{2 L_{2}\left(i_{m}\right)},
\end{aligned}
$$

where $\mathrm{R}_{1}, \mathrm{R}_{2}$ are stator and rotor resistances respectively. The index " $\mathrm{m}$ " in (2) is used to denote the parameter's dependency on magnetizing current $i_{m}$.

From the practical assumption that there is a constant relationship between any pair of $\mathrm{L}_{1}\left(\mathrm{i}_{\mathrm{m}}\right), \mathrm{L}_{2}\left(\mathrm{i}_{\mathrm{m}}\right)$ and $\mathrm{L}_{\mathrm{m}}\left(\mathrm{i}_{\mathrm{m}}\right)$ it can be concluded that: $\quad \alpha_{\mathrm{m}} \mathrm{L}_{\mathrm{m}}\left(\mathrm{i}_{\mathrm{m}}\right)=\alpha \mathrm{L}_{\mathrm{m}}=$ const and $\mu_{1 \mathrm{~m}}=\mu_{1}=$ const where $\mathrm{L}_{\mathrm{m}}=\mathrm{const}-$ the machine magnetizing inductance at the rated flux.

Consider the IM model (1) and assume that:

A1. The stator currents and rotor speed are available for measurement.

A.2. All motor parameters are known and constant. All saturation-dependent parameters are known function of a magnetizing current.

A3. The torque reference trajectory $\mathrm{T}^{*}$ is a smooth and bounded function together with its first and second time derivatives.
A.4. The nonlinear function of flux reference $\psi^{*}\left(\left|\mathrm{~T}^{*}\right|\right)=\psi_{0}^{*}+\psi_{\text {opt }}^{*}\left(\mathrm{~T}^{*}\right)>0$, which provides flux level optimization as a function of desired torque to achieve MTA condition is known smooth function together with the first and second time derivatives, $\psi^{*}(0)=\psi_{0}^{*}, \psi_{0}^{*}>0-$ small initial flux reference when $T^{*}=0$.

Under these assumptions, it is required to design a torque controller which guarantees that the following control objectives are achieved:

CO1. Asymptotic torque tracking with all internal signals bounded, i.e.

$$
\lim _{t \rightarrow \infty} \tilde{T}=0
$$

where $\tilde{\mathrm{T}}=\mathrm{T}-\mathrm{T}^{*}$ is torque tracking error;

$\mathrm{CO} 2$. Maximization of Torque per Ampere ratio in steady state:

$$
\max \left(\frac{\mathrm{T}}{\mathrm{I}_{1}}\right),
$$

where $I_{1}=\sqrt{i_{d}^{2}+i_{q}^{2}}$ is a stator current magnitude.

CO3. Asymptotic field orientation, i.e.

$$
\lim _{\mathrm{t} \rightarrow \infty} \psi_{\mathrm{q}}=0
$$

\section{MTA CONTROLLER DESIGN}

Let consider current-fed IM with currents $i_{d}$ and $i_{q}$ are considered as control inputs. A reduced order flux observer for (1) is given by

$$
\begin{aligned}
& \dot{\hat{\psi}}=-\alpha_{\mathrm{m}} \hat{\psi}+\alpha \mathrm{L}_{\mathrm{m}} \mathrm{i}_{\mathrm{d}}, \\
& \dot{\varepsilon}_{0}=\omega_{0}=\omega+\frac{\alpha \mathrm{L}_{\mathrm{m}} \mathrm{i}_{\mathrm{q}}}{\hat{\psi}},
\end{aligned}
$$

where $\hat{\psi}$ - estimation of rotor flux magnitude, which guaranties that flux estimation errors

$$
\begin{aligned}
& \tilde{\psi}_{\mathrm{d}}=\psi_{\mathrm{d}}-\hat{\psi}, \\
& \tilde{\psi}_{\mathrm{q}}=\psi_{\mathrm{q}},
\end{aligned}
$$

exponentially decay to zero.

Using errors definition (7) and torque equation of IM in (1), the torque error dynamics can be presented as

$$
\begin{aligned}
& \dot{\tilde{\mathrm{T}}}=-\alpha_{\mathrm{m}} \mathrm{T}^{*}-\dot{\mathrm{T}}^{*}+\alpha \mathrm{L}_{\mathrm{m}} \mu_{1} \mathrm{i}_{\mathrm{d}} \mathrm{i}_{\mathrm{q}}+\mu_{1} \hat{\psi} \dot{\mathrm{i}}_{\mathrm{q}}- \\
& -\alpha_{\mathrm{m}} \tilde{\mathrm{T}}+\tilde{\varphi}\left(\mathrm{t}, \tilde{\psi}_{\mathrm{d}}, \tilde{\psi}_{\mathrm{q}}\right),
\end{aligned}
$$

where $\tilde{\varphi}\left(\mathrm{t}, \tilde{\psi}_{\mathrm{d}}, \tilde{\psi}_{\mathrm{q}}\right)=\mu_{1}\left[\left(\dot{\mathrm{i}}_{\mathrm{q}}+\omega_{2} \mathrm{i}_{\mathrm{d}}\right) \tilde{\psi}_{\mathrm{d}}-\left(\dot{\mathrm{i}}_{\mathrm{d}}-\omega_{2} \mathrm{i}_{\mathrm{q}}\right) \tilde{\psi}_{\mathrm{q}}\right]$.

Using (8) the dynamic output feedback linearizing torque controller is designed as follows: 


$$
\dot{\mathrm{i}}_{\mathrm{q}}=-\frac{\alpha \mathrm{L}_{\mathrm{m}}}{\hat{\psi}} \mathrm{i}_{\mathrm{d}} \mathrm{i}_{\mathrm{q}}+\frac{1}{\mu_{1} \hat{\psi}}\left[\alpha_{\mathrm{m}} \mathrm{T}^{*}+\dot{\mathrm{T}}^{*}\right]
$$

Substituting (9) into (8) the resulting torque-flux error dynamic becomes

$$
\begin{gathered}
\dot{\tilde{\mathrm{T}}}=-\alpha_{\mathrm{m}} \tilde{\mathrm{T}}+\tilde{\varphi}_{1}\left(\mathrm{t}, \tilde{\Psi}_{\mathrm{d}}, \tilde{\Psi}_{\mathrm{q}}\right) \\
\dot{\tilde{\Psi}}_{\mathrm{d}}=-\alpha_{\mathrm{m}} \tilde{\Psi}_{\mathrm{d}}+\omega_{2} \tilde{\Psi}_{\mathrm{q}}, \\
\dot{\tilde{\Psi}}_{\mathrm{q}}=-\alpha_{\mathrm{m}} \tilde{\Psi}_{\mathrm{q}}-\omega_{2} \tilde{\Psi}_{\mathrm{d}}, \\
\tilde{\varphi}_{1}\left(\mathrm{t}, \tilde{\Psi}_{\mathrm{d}}, \tilde{\psi}_{\mathrm{q}}\right)=\left(\alpha_{\mathrm{m}} \mathrm{T}^{*}+\dot{\mathrm{T}}^{*}\right) \frac{\tilde{\Psi}_{\mathrm{d}}}{\hat{\psi}}-\mu_{1}\left(\dot{\mathrm{i}}_{\mathrm{d}}-\frac{\alpha \mathrm{L}_{\mathrm{m}}}{\hat{\psi}} \mathrm{i}_{\mathrm{q}}^{2}\right) \tilde{\Psi}_{\mathrm{q}} .
\end{gathered}
$$

In order to control the estimated flux magnitude in (6) the following PI controller is employed:

$$
\begin{aligned}
& \mathrm{i}_{\mathrm{d}}=\frac{1}{\alpha \mathrm{L}_{\mathrm{m}}}\left(\alpha_{\mathrm{m}} \psi^{*}+\dot{\psi}^{*}-\mathrm{k}_{\psi} \tilde{\psi}-\mathrm{x}_{\psi}\right) \\
& \dot{\mathrm{x}}_{\psi}=\mathrm{k}_{\psi \mathrm{i}} \tilde{\psi}
\end{aligned}
$$

where: $\tilde{\psi}=\hat{\psi}-\psi^{*}$ is flux (estimated) tracking error; $\left(\mathrm{k}_{\psi}, \mathrm{k}_{\psi \mathrm{i}}\right)>0$ are the controller proportional and integral gains respectively.

Note that internal dynamics of the torque controller is stable for $\hat{\psi}>0, \mathrm{i}_{\mathrm{d}}>0$.

From (6) and (12), the error dynamic can be derived as

$$
\begin{aligned}
& \dot{\tilde{\psi}}=-\left(\alpha_{\mathrm{m}}+\mathrm{k}_{\psi}\right) \tilde{\psi}-\mathrm{x}_{\psi} \\
& \dot{\mathrm{x}}_{\psi}=\mathrm{k}_{\psi \mathrm{i}} \tilde{\psi}
\end{aligned}
$$

System (13) is second order linear and stable. If $\tilde{\psi}(0)=0$ then all solutions of (13) $\tilde{\psi}(\mathrm{t}) \equiv 0 \forall \mathrm{t} \geq 0$. In order to avoid singularity in (6), (9) and satisfy condition $\tilde{\psi}(0)=0$ in (13), the observer initialization is selected as:

$$
\hat{\psi}(0)=\psi_{0}^{*}>0, \varepsilon_{0}(0)=0 .
$$

As the result of the proposed tuning and flux observer initialization, the following is established: $\hat{\psi}(t)>0$ and $i_{d}(t)$ is bounded. The time derivative of $i_{d}$

$$
\dot{\mathrm{i}}_{\mathrm{d}}=\frac{1}{\alpha \mathrm{L}_{\mathrm{m}}}\left\{\alpha_{\mathrm{m}} \dot{\psi}^{*}+\ddot{\psi}^{*}-\mathrm{k}_{\psi}\left[-\left(\alpha_{\mathrm{m}}+\mathrm{k}_{\psi}\right) \tilde{\psi}-\mathrm{x}_{\psi}\right]-\dot{\mathrm{x}}_{\psi}\right\}
$$

is also bounded and known.

Two nonlinear subsystems (10) and (11) are connected in series. Since $\lim _{\mathrm{t} \rightarrow \infty}\left(\tilde{\psi}_{\mathrm{d}}, \tilde{\psi}_{\mathrm{q}}\right)=0, \mathrm{~T}^{*}, \dot{\mathrm{T}}^{*}, \dot{\mathrm{i}}_{\mathrm{q}}, \mathrm{i}_{\mathrm{q}}, \mathrm{i}_{\mathrm{d}}, \dot{\mathrm{i}}_{\mathrm{d}}$ are bounded, one can conclude that $\lim _{\mathrm{t} \rightarrow \infty} \tilde{\varphi}_{1}\left(\mathrm{t}, \tilde{\psi}_{\mathrm{d}}, \tilde{\psi}_{\mathrm{q}}\right)=0$ and $\tilde{\mathrm{T}}$ in (10) exponentially decays to zero. From this analysis it follows that the control objectives CO.1 - CO.3 are globally achieved.
In actual IM drives the currents $i_{d}$ and $i_{q}$ in (1) are not available as control inputs. Solutions to (9) and equation (12) represent only their desired dynamics, providing reference trajectories $\mathrm{i}_{\mathrm{d}}{ }^{*}$ and $\mathrm{i}_{\mathrm{q}}{ }^{*}$ for the inner current control loops. Applying similar to [4] design steps the following is constructed:

- modified flux observer

$$
\begin{aligned}
& \dot{\hat{\psi}}=-\alpha_{\mathrm{m}} \hat{\psi}+\alpha \mathrm{L}_{\mathrm{m}} \mathrm{i}_{\mathrm{d}}, \\
& \dot{\varepsilon}_{0}=\omega_{0}=\omega+\frac{\alpha \mathrm{L}_{\mathrm{m}} \mathrm{i}_{\mathrm{q}}}{\hat{\psi}}+\frac{\gamma_{1} \beta_{\mathrm{m}} \omega \tilde{\mathrm{i}}_{\mathrm{d}}}{\hat{\psi}},
\end{aligned}
$$

- d-axis current controller

$$
u_{d}=\sigma_{m}\left(\gamma_{m} i_{d}^{*}-\omega_{0} i_{q}-\alpha_{m} \beta_{m} \hat{\psi}+\dot{i}_{d}^{*}-k_{i d} \tilde{i}_{d}\right)
$$

- q-axis current controller

$$
\begin{aligned}
& \mathrm{u}_{\mathrm{q}}=\sigma_{\mathrm{m}}\left(\gamma_{\mathrm{m}} \mathrm{i}_{\mathrm{q}}^{*}+\omega_{0} \mathrm{i}_{\mathrm{d}}+\beta_{\mathrm{m}} \omega \hat{\psi}+\dot{\mathrm{i}}_{\mathrm{q}}^{*}-\mathrm{k}_{\mathrm{iq}} \tilde{\mathrm{i}}_{\mathrm{q}}+\mathrm{x}_{\mathrm{q}}\right), \\
& \dot{\mathrm{x}}_{\mathrm{q}}=-\mathrm{k}_{\mathrm{iiq}} \tilde{\mathrm{i}}_{\mathrm{q}},
\end{aligned}
$$

where $\tilde{i}_{d}=i_{d}-i_{d}^{*}$ and $\tilde{i}_{q}=i_{q}-i_{q}^{*}$ are current tracking errors, $\left(\mathrm{k}_{\mathrm{id}}, \mathrm{k}_{\mathrm{iq}}\right)>0$ are the current controller's proportional gains, $\mathrm{k}_{\mathrm{iiq}}>0$ is the integral gain, $\gamma_{1}$ - tuning gain of the observer (16). It can be shown that full order torque-flux controller, given by (9), (12), (16) - (18), guarantees with suitable tuning that equilibrium point $\lim _{t \rightarrow \infty}\left(\tilde{T}, \tilde{\psi}_{d}, \tilde{\psi}_{q}, \tilde{\psi}, x_{\psi}, \tilde{i}_{d}, \tilde{i}_{q}, x_{q}\right)=0$ is locally asymptotically stable.

The block diagram of the proposed controller is shown in Fig. 1. The algorithm (17), (18) takes into account the machine magnetizing curve in motor parameters as given by (2).

Remark. All MTA controllers are designed to achieve optimization objectives when electromagnetic torque is constant or slowly varying. Flux controller (12) provides flux trajectory tracking with specified dynamic performances. For "slow" torque trajectory the MTA conditions can be achieved faster due to flux regulation. "Fast" torque trajectory requires fast flux regulation that leads to significant increase of the stator current magnitude dynamic component and as a result the torque per Ampere ratio is reduces. In order to resolve this problem, the flux controller (12) can be eliminated from the control algorithm if a fast torque trajectory is required to be tracked. In this case an optimal relation $i_{d}^{*}\left(\left|T^{*}\right|\right)[5]$ should be used instead of $\psi^{*}\left(\left|\mathrm{~T}^{*}\right|\right)$. Note that computation of both MTA relations requires knowledge of motor magnetizing curve. As an illustrative example, Fig. 2 shows the magnetizing curve $\psi\left(\mathrm{i}_{\mathrm{m}}\right)$ as well as the MTA relations for $\psi^{*}\left(|\mathrm{~T}|^{*}\right)$ (Fig. 2b) and $\mathrm{i}_{\mathrm{d}}^{*}\left(\left|\mathrm{~T}^{*}\right|\right)$ (Fig. 2c) calculated for the $5.5 \mathrm{~kW}$ induction machine, whose rated parameters are given in Appendix. 


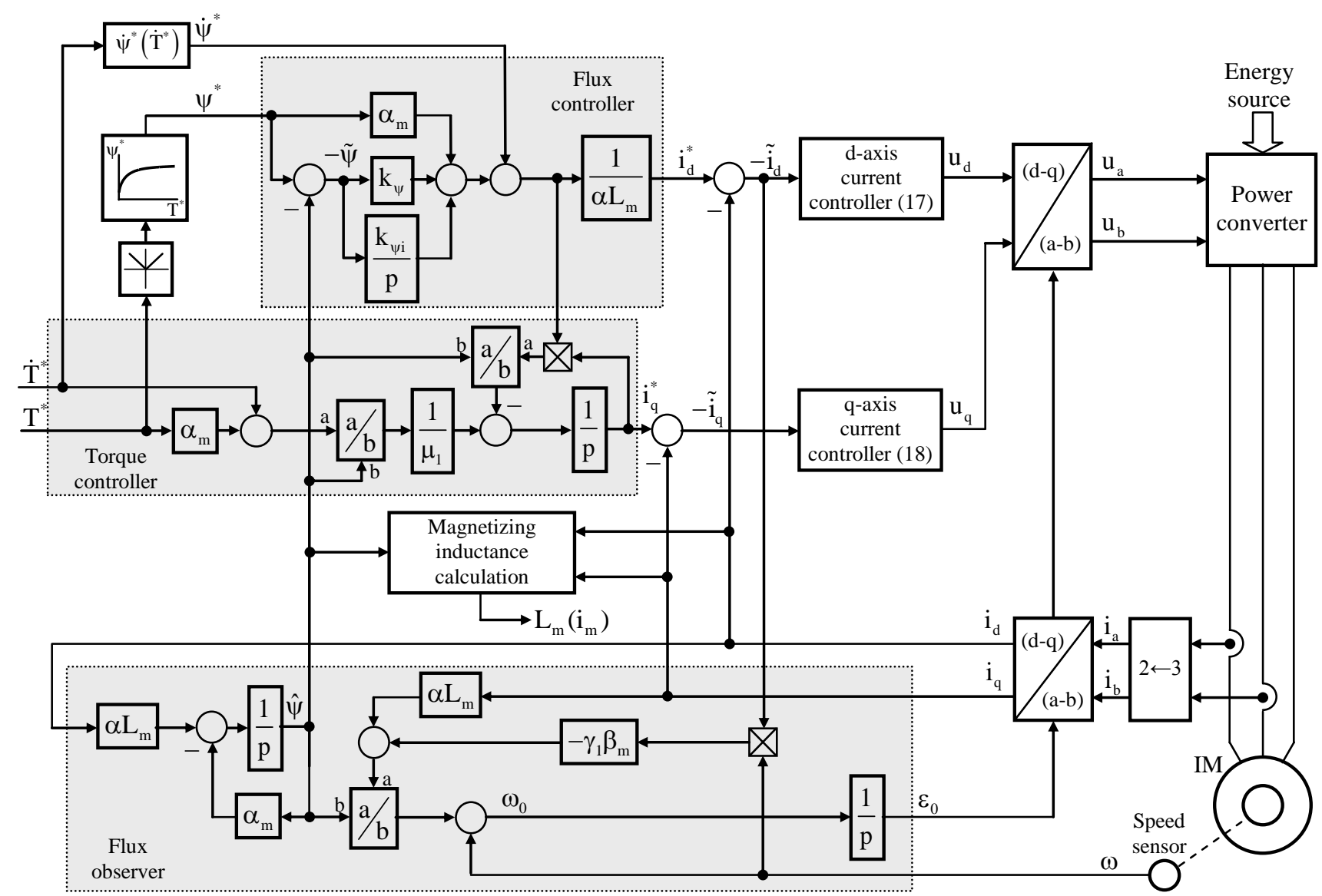

Fig. 1. Block diagram of the torque control system with dynamic feedback linearizing controller

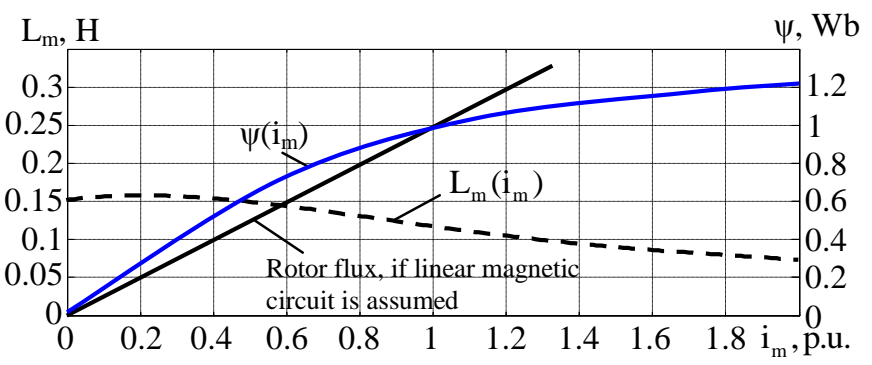

a)

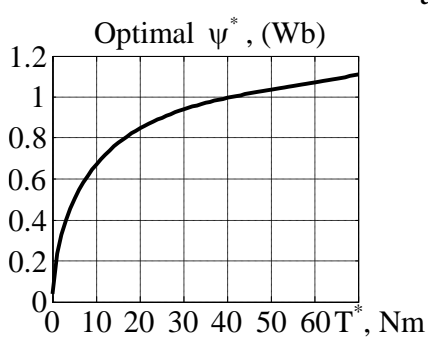

b)

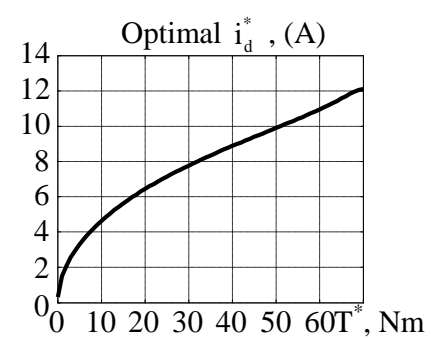

c)
Fig. 2. Magnetizing curve, magnetizing inductance and MTA relationships for the IM in Appendix

\section{EXPERIMENTAL RESULTS}

The experiments are carried out using the Rapid Prototyping Station, which includes (Fig. 3): $5.5 \mathrm{~kW}$ induction motor; current controlled loading DC-machine; $50 \mathrm{~A}$ and $380 \mathrm{~V}$ three-phase PWM controlled inverter with switching frequency $2.5 \mathrm{kHz}$; DSP controller (based on TMS320F28335) which performs data acquisition, implements control algorithms with programmable tracing of selected variables; personal computer. The motor speed is measured by a 2500 pulse/revolution optical encoder. The sampling time is set at $200 \mu \mathrm{sec}$.

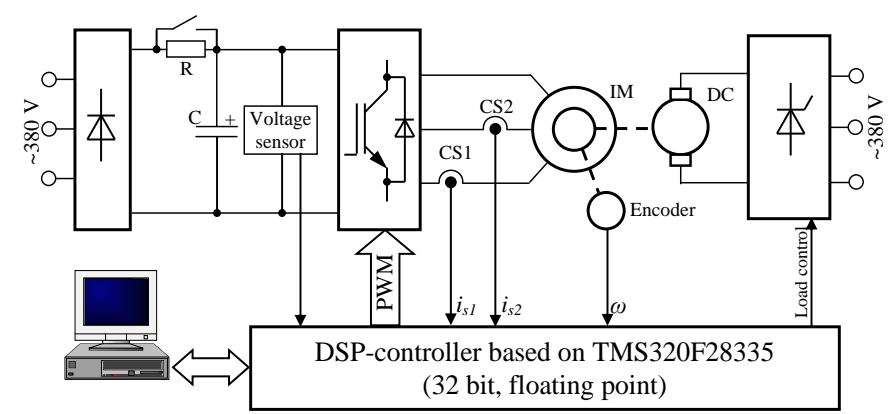

Fig. 3. Experimental set-up of electromechanical system with induction motor

At the first stage the system efficiency characteristics have been compared experimentally for three types of controllers: standard vector control with constant flux operation [8] (IFOC), 
controller based on classic maximization of torque per Ampere ratio for linear magnetic circuit (MTAL) and controller based on MTA strategy for saturated induction motor with flux regulation (MTASF).

The angular velocity during the tests was stabilized at the value of $10 \mathrm{rad} / \mathrm{s}$, so the mechanical power at the rated load was $350 \mathrm{~W}$. Such conditions were selected in order to demonstrate the active power losses optimization which are generally independent from the rotor speed.

During the first series of tests the following operating sequences were used: the initial time interval $(0 \leq \mathrm{t}<1 \mathrm{~s})$ is used to maintain the minimum flux reference $\left(\psi_{0}^{*}=0.05 \mathrm{~Wb}\right)$; at $\mathrm{t}=1 \mathrm{~s}$ the smooth torque reference shown in Fig. 4 and reaching the torque of $7 \mathrm{Nm}$ ( $20 \%$ of the rated one) is applied; at each next time interval of $1.5 \mathrm{~s}$ the torque reference increases by $7 \mathrm{Nm}$; at $\mathrm{t}=7 \mathrm{~s}$ the torque reference reaches the rated value of $35 \mathrm{Nm}$; and at $\mathrm{t}=8 \mathrm{~s}$ the torque reference decreases to zero.

In Fig. 5a the Torque per Ampere ratio for compared systems is presented. These curves clearly confirm that the MTASF system provides better Torque per Ampere ratio in whole range of operation. MTAL system based on classic MTA criterion [3] improves the torque per Ampere ratio in compare to IFOC system only for torques values below $60 \%$ of the machine rated value.

From Fig. $5 \mathrm{~b}$ it can be seen that MTAL controller works with constant value of power factor equal to 0.707 in the region where optimization according to MTA criterion is possible. IFOC controller provides lower power factor within the same region. At higher torques IFOC and MTAL provide the same value, while MTASF controller has the highest power factor for entire torque range. The result of experimental study has proved that MTASF provides better efficiency as well, as reported in Fig. 5c.

From transients depicted in Fig. 5d it can be concluded that the flux controller (12) provides fast flux regulation and hence the MTA condition is achieved much faster. However it should be noted that faster flux regulation requires more current during transients if torque reference is not constant. In order to investigate these conditions the second series of tests was undertaken. During these tests two different torque reference trajectories where used. First type of trajectory is bipolar sinusoidal wave with frequency $\mathrm{f}_{\mathrm{T}}$ as depicted in Fig. 6a. In order to track this trajectory with MTA optimization it is necessary to reduce the flux level to minimum when the torque reference goes to zero. After crossing zero point the torque reference increases into opposite direction and flux reference should be increased as well. Hence this type of torque trajectory represents one of the worst cases, when deep and fast flux regulation is required.

The second torque trajectory, reported in Fig. 7a, is quite simple for tracking by flux subsystem. During this test the torque reference arises to value of $20 \mathrm{Nm}$ ( $57 \%$ of rated) with bounded first and second derivatives. Starting from $t=4 \mathrm{~s}$ it is required to track sinusoidal torque trajectory with maximum and minimum values equals to $35 \mathrm{Nm}$ (100\% of rated) and $5 \mathrm{Nm}(14 \%$ of rated) correspondingly.

Using selected trajectories with different frequencies $\mathrm{f}_{\mathrm{T}}$ the following controllers were tested: IFOC, MTASF and MTA with flux controller (12) replaced by direct setting of optimal excitation current $i_{d}^{*}\left(\left|T^{*}\right|\right)$ (MTAS). After each test the rms value of torque per Ampere ratio for the one period of sinusoidal torque reference was recorded.
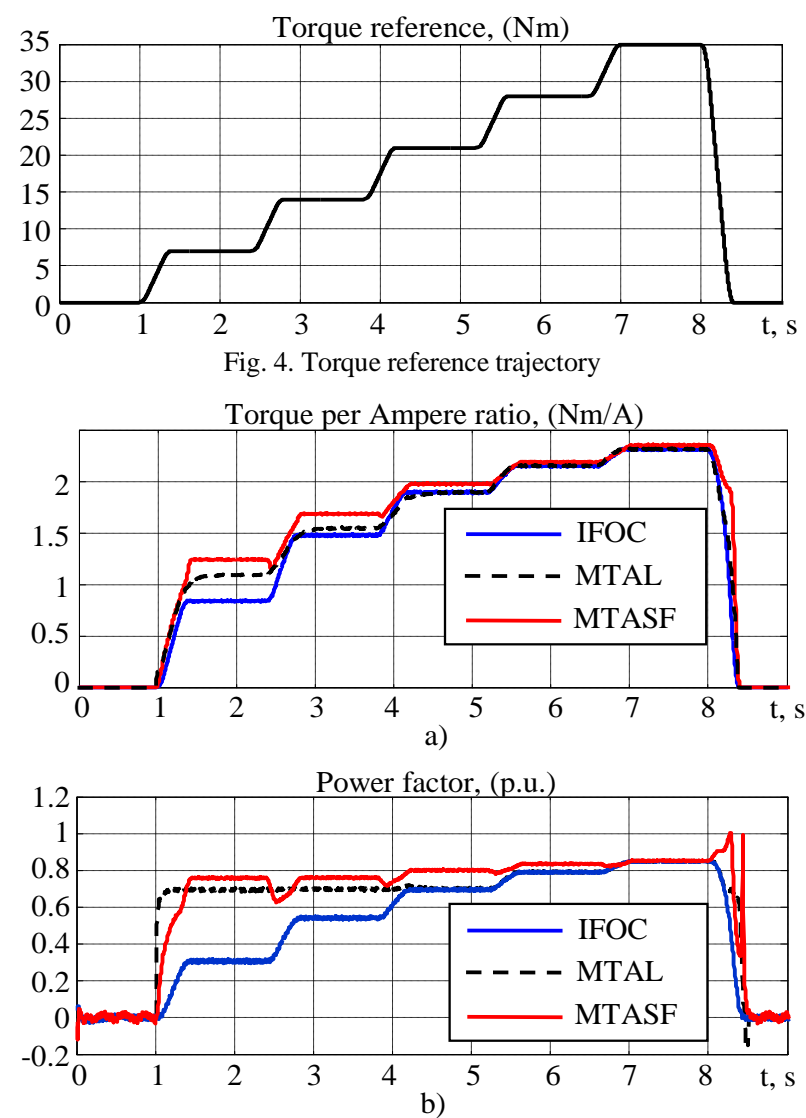

Efficiency, (p.u.)

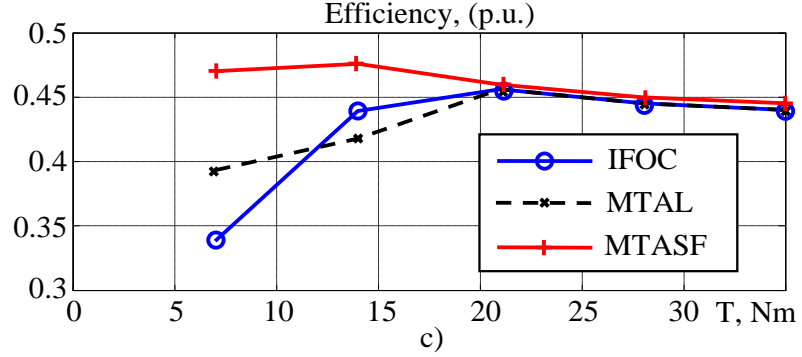

Estimated flux, (Wb)

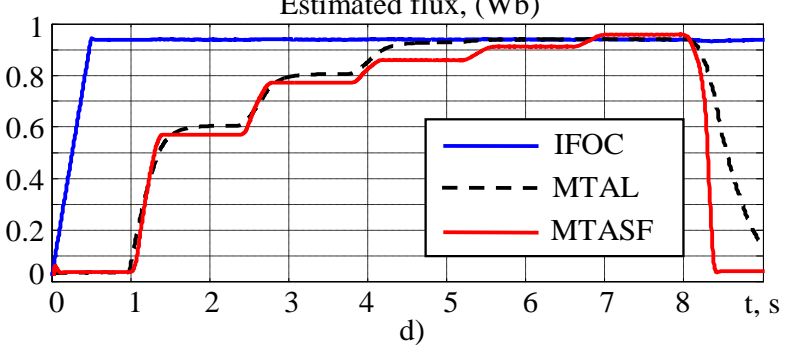

Fig. 5. Torque per Ampere ratio, efficiency, power factor and estimated rotor flux during torque tracking

The waveforms of stator current magnitude $\left(\mathrm{f}_{\mathrm{T}}=0.2 \mathrm{~Hz}\right.$ and $f_{T}=1 \mathrm{~Hz}$ ) are shown in Fig. 6b, and Fig. 6c (see also Fig. 7b, $\mathrm{f}_{\mathrm{T}}=0.2 \mathrm{~Hz}$ and Fig. $7 \mathrm{c}, \mathrm{f}_{\mathrm{T}}=5 \mathrm{~Hz}$ ). From presented transients it follows that MTASF and MTAS provides similar performances when torque trajectory is slow. When faster torque trajectory is applied, MTASF generates significant current spikes due to fast flux regulation. Hence bipolar sinusoidal trajectories with frequencies above $1 \mathrm{~Hz}$ are not applicable for MTASF 
algorithm. In the case of unipolar reference MTASF controller does not provide MTA optimization if $\mathrm{f}_{\mathrm{T}}$ higher then $4-5 \mathrm{~Hz}$.

From the other hand, MTAS algorithm with direct optimal excitation current setting provides torque tracking with MTA optimization for faster torque trajectories and does not lead to spikes of stator current during zero crossings in torque reference.
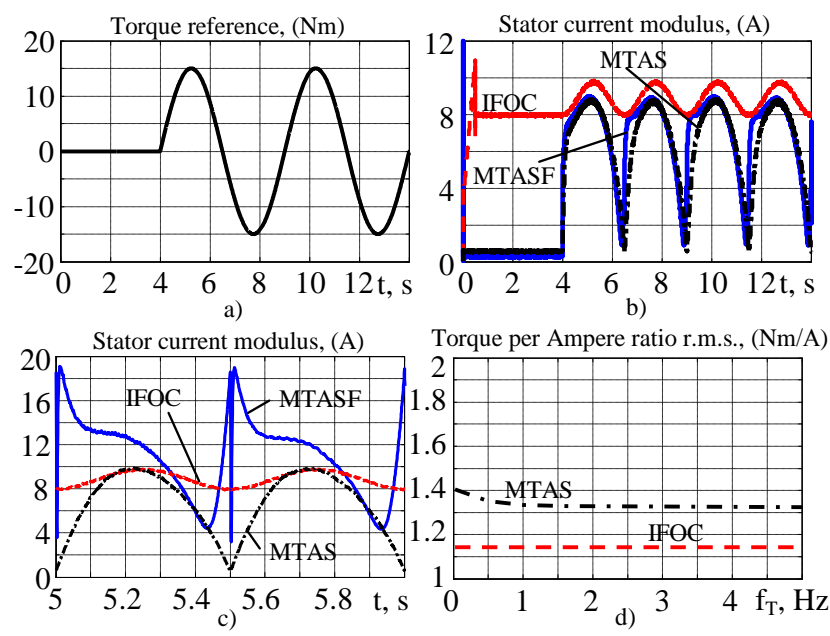

Fig. 6. Transients during bipolar sinusoidal reference
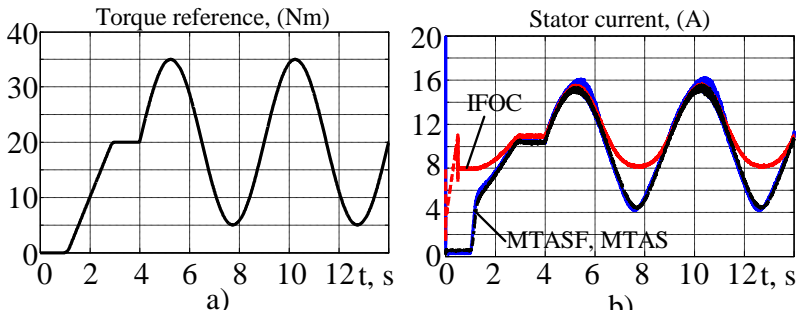

b)

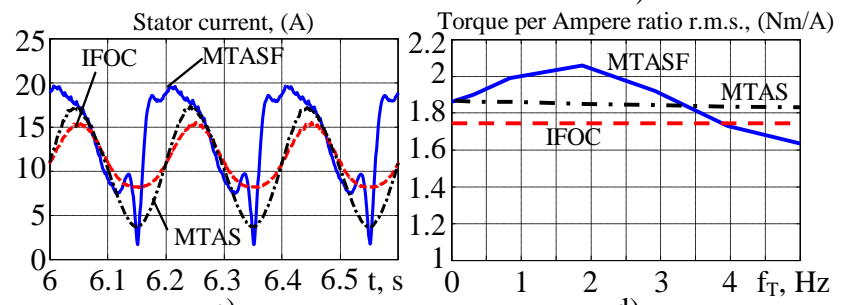

c)

Fig. 7. Transients during unipolar sinusoidal reference

\section{CONCLUSIONS}

A novel direct field-oriented control algorithm for induction motors based on dynamic output-feedback linearizing technique has been designed and experimentally verified. Nonlinear dynamic controller guarantees local asymptotic torque tracking and torque per Ampere ratio maximization when the developed torque is constant or slowly varying.

The advantages of MTA controller designed for saturated IM with respect to standard field-oriented controllers with constant excitation are demonstrated. The MTA controller provides not only higher torque per Ampere ratio but reduces active power consumption improving the drive energy efficiency and increasing power factor. It is also shown that the active power losses with designed controller can be reduced up to $30 \%$ compare to standard IFOC with constant flux operation for small developed torques.
Flux controller designed for MTA algorithms provides asymptotic flux tracking and improves system performance if torque reference is slow enough. For the fast torque trajectory tracking it is necessary to replace flux controller by direct setting of optimal excitation current using magnetizing curve. In this case a better current dynamics can be achieved. Nevertheless, further investigations are needed to establish the practical limitations for applicability of MTA control if torque dynamics cannot be neglected.

It is demonstrated experimentally that the drive control system based on MTA controller designed for saturated IM is an attractive solution for technological applications where high dynamic performance is not required, for example - in electric vehicle drives.

\section{REFERENCES}

[1] Chiasson J. "Modeling and High Performance Control of Electric Machines “- John Wiley \& Sons, 2005. - 734 p.

[2] Consoli A., Scarcella G., Scelba G. and Testa A. "Induction Motor Sensorless Control Based on a Maximum Torque per Ampere Approach" Record of the Industry Applications Conference, 2003. 38th IAS Annual Meeting. Conference, vol. 3, pp. 2005-2011, 2003.

[3] Wasynchuk O., Sudhoff S.D., Corsine K., Tichenor J., Krause P., Hansen I., Taylor L. "A maximum torque per Ampere control strategy for induction motor drives" IEEE Trans. on Energy Conversion. -1998. Vol.13, No.2. -pp.163-169.

[4] S.Dymko, S.Peresada, R.Leidhold "Torque Control of Saturated Induction Motor with Torque per Ampere Ratio Maximization” in Proc. 2014 IEEE International Conference on Intelligent Energy and Power Systems, 2-6 Jun., Kyiv, 2014, pp.251-256.

[5] Bozhko S., Dymko S., Kovbasa S., Peresada S. "MTA Control for Traction IM Drives: Theory and Experimental Results" Proceedings on 2015 IEEE International Conference on Electrical Systems for Aircraft, Railway, Ship Propulsion and Road Vehicles (ESARS-2015): Paper SS2.1.5. - Aachen, Germany, 2015. - 6p.

[6] E.Levi "A Unified Approach to Main Flux Saturation Modelling in D-Q Axis Models of Induction Machines" IEEE Transactions on Energy Conversion, vol. 10, no. 3, pp.455-461, 1995.

[7] E.Levi "Impact of Cross-Saturation on Accuracy of Saturated Induction Machine Models" IEEE Transactions on Energy Conversion, vol. 12, no. 3, pp.211-216, 1997.

[8] Peresada S. and Tonielli A. "High-performance robust speed-flux tracking controller for induction motor" Int. J. Adapt. Control Signal Process., vol. 14, pp. 177-200, 2000.

\section{APPENDIX}

\section{Parameter}

Rated torque

Rated stator current magnitude

Rated speed

Stator resistance

Rotor resistance

Stator (rotor) inductance

Mutual inductance

Total inertia

Number of pole pairs
Value Units

10.5 A

$154 \mathrm{rad} / \mathrm{s}$

$0.94 \Omega$

$0.65 \Omega$

$0.123 \mathrm{H}$

$0.117 \quad \mathrm{H}$

$0.16 \mathrm{~kg} \cdot \mathrm{m}^{2}$
$35 \quad \mathrm{Nm}$ 